\title{
Matching unrelated stimuli with same discriminative functions: training order effects
}

\author{
Franck Carpentier $^{\mathrm{a}}$, Paul M. Smeets ${ }^{\mathrm{a}, *}$, Dermot Barnes-Holmes ${ }^{\mathrm{b}}$ \\ a Department of Psychology, Leiden University, P.O. Box 9555, 2300 RB Leiden, The Netherlands \\ ${ }^{\mathrm{b}}$ National University of Ireland at Maynooth, Maynooth, Ireland
}

Accepted 3 September 2002

\begin{abstract}
Previous research has shown that after training simple discriminations (A1+/A2-, B1+/B2-), bringing these tasks under conditional control $(\mathrm{J} 1-\mathrm{A} 1, \mathrm{~J} 2-\mathrm{A} 2)$ leads to transfer of discriminative control $(\mathrm{J} 1+/ \mathrm{J} 2-)$ and to generalized matching on the basis of same discriminative functions (e.g. J1-B1, J2-B2). The same occurs when conditional discriminations are trained (D1-E1, D2-E2; F1-G1, F2-G2). When the subjects are then trained to demonstrate correct relations (D1-E1, D2-E2) when given X1 and to demonstrate incorrect relations when given X2 (XD-E), transfer of discriminative control $(\mathrm{X} 1+/ \mathrm{X} 2-)$ and generalized matching on the basis of same discriminative functions emerges (e.g. X1F1-G1, X2F1-G2). The present study investigated if these performances are dependent on the training and/or testing order. In Experiment 1, the lower-order contingency tasks were trained before the higher-order contingency tasks $(\mathrm{A} 1+/ \mathrm{A} 2-, \mathrm{B} 1+/ \mathrm{B} 2-$ before $\mathrm{J}-\mathrm{A}$, and $\mathrm{D}-\mathrm{E}, \mathrm{F}-\mathrm{G}$ before $\mathrm{XD}-\mathrm{E})$. Half the subjects received the $\mathrm{J}-\mathrm{B}$ test before the more complex $\mathrm{XF}-\mathrm{G}$ test (Condition $\mathrm{A}$ ), while for the other subjects, this testing order was reversed (Condition B). Finally, all subjects received additional tests in which they were given the opportunity to demonstrate the discriminative properties of the $\mathrm{J}$ and $\mathrm{X}$ stimuli $(\mathrm{J} 1+/ \mathrm{J} 2-, \mathrm{X} 1+/ \mathrm{X} 2-)$, and to match the $\mathrm{A}, \mathrm{J}$, and $\mathrm{X}$ stimuli with newly introduced stimuli of same discriminative properties (e.g. J1-POLITE, J2-RUDE). Experiment 2 was the same except that the training order was reversed $(\mathrm{J}-\mathrm{A}$ before $\mathrm{A} 1+/ \mathrm{A} 2-, \mathrm{B} 1+/ \mathrm{B} 2-$, and $\mathrm{XD}-\mathrm{E}$ before $\mathrm{D}-\mathrm{E}, \mathrm{F}-\mathrm{G})$. The results were affected by the training order but not by the testing order. Transfer of discriminative functions and generalized matching on the basis of same functions only occurred reliably when the lower-order contingency tasks were trained first. A stimulus-control account of the data is offered.
\end{abstract}

(C) 2002 Elsevier Science B.V. All rights reserved.

Keywords: Training order; Discriminative functions; Transfer; Stimulus equivalence; Adults

\section{Introduction}

Stimulus equivalence research has shown that match-to-sample training leads to all directly and

\footnotetext{
* Corresponding author

E-mail address: smeets@fsw.leidenuniv.nl (P.M. Smeets).
}

indirectly related stimuli becoming functionally substitutable for one another. After being trained to match sample $\mathrm{A} 1$ with comparisons $\mathrm{B} 1$ and $\mathrm{C} 1$, and sample $\mathrm{A} 2$ with comparisons $\mathrm{B} 2$ and $\mathrm{C} 2$ (A1$\mathrm{B} 1, \mathrm{~A} 2-\mathrm{B} 2$; $\mathrm{A} 1-\mathrm{C} 1, \mathrm{~A} 2-\mathrm{C} 2)$, most humans match, without further training, same-class $\mathrm{B}$ and $\mathrm{C}$ stimuli $(\mathrm{B} 1-\mathrm{C} 1, \mathrm{~B} 2-\mathrm{C} 2 ; \mathrm{C} 1-\mathrm{B} 1, \mathrm{C} 2-\mathrm{B} 2)$. 
Likewise, when one member of each class is given a new function (e.g. A1 $\rightarrow$ clap, A2 $\rightarrow$ wave), the other members of these classes typically are affected the same way (e.g. C1 $\rightarrow$ clap, C2 $\rightarrow$ wave). For extensive reviews, see Sidman (1994, 2000).

Equivalence classes, however, are not restricted to samples and comparisons; they can also include stimuli that serve as feedback. Studies by Dube and Mclvane (1995), Dube et al. (1989), Schenk (1994) have shown that class-related feedback leads to class formation of otherwise unrelated stimuli. In the study by Schenk (1994), for example, 5-year-old preschool children were trained on four sets of identity matching tasks. All correct responses were followed by the delivery of a token, some by a red token $(\mathrm{A} 1-\mathrm{A} 1, \mathrm{~B} 1-\mathrm{B} 1$, $\mathrm{C} 1-\mathrm{C} 1, \mathrm{D} 1-\mathrm{D} 1)$, others by a blue token $(\mathrm{A} 2-\mathrm{A} 2$, B2-B2, C2-C2, D2-D2). During subsequent tests, most children related all same color-class stimuli conditionally with one another (A1-B1$\mathrm{C} 1-\mathrm{D} 1$ and $\mathrm{A} 2-\mathrm{B} 2-\mathrm{C} 2-\mathrm{D} 2)$.

Similar findings have been reported with classunrelated feedback (Pérez-González, 1994; PérezGonzález and Serna, in press). For example, in the Pérez-González (1994) study, subjects were trained on three $\mathrm{A}-\mathrm{B}$ relations $(\mathrm{A} 1-\mathrm{B} 1, \mathrm{~A} 2-\mathrm{B} 2, \mathrm{~A} 3-\mathrm{B} 3)$ and on similar $\mathrm{P}-\mathrm{Q}$ relations. Then they were taught to relate $\mathrm{AB}$ compounds with same-class elements to $\mathrm{X} 1$ (e.g. $\mathrm{A} 1 \mathrm{~B} 1-\mathrm{X} 1$ ) and $\mathrm{AB}$ compounds with different-class elements to $\mathrm{X} 2$ (e.g. A1B2-X2). During subsequent probes, most subjects related PQ compounds with same-class elements to X1 (e.g. P1Q1-X1) and PQ compounds with different-class elements to X2 (e.g. P2Q1X2). Although Pérez-González offered a different account, the subjects may have matched stimuli associated with same differential feedback (Carpentier et al., 2002a). During the $\mathrm{A}-\mathrm{B}$ and $\mathrm{P}-\mathrm{Q}$ training, the subjects received positive feedback when demonstrating $\mathrm{A} 1-\mathrm{B} 1, \mathrm{~A} 2-\mathrm{B} 2, \mathrm{P} 1-\mathrm{Q} 1$, and $\mathrm{P} 2-\mathrm{Q} 2$ and negative feedback when demonstrating $\mathrm{A} 1-\mathrm{B} 2, \mathrm{~A} 2-\mathrm{B} 1, \mathrm{P} 1-\mathrm{Q} 2, \mathrm{P} 2-\mathrm{Q} 1$. As a result, two sets of separable discriminative compounds were formed (Dougher and Markham, 1994; Stromer et al., 1993): an S+ set (A1B1, A2B2, A3B3, P1Q1, P2Q2, P3Q3) and an $\mathrm{S}-$ set (e.g. A1B2, A2B1, P1Q2, P2Q1). During the AB-X training, the subjects were trained to match a subset of the $\mathrm{S}+$ stimuli with $\mathrm{X} 1$, and a subset of the $\mathrm{S}-$ stimuli with $\mathrm{X} 2$. As a result, transfer from $\mathrm{AB}$ to $\mathrm{X}$ should be expected (e.g. A1B1 +, A1B1 $\mathrm{X} 1$, hence $\mathrm{X} 1+; \mathrm{A} 1 \mathrm{~B} 2-, \mathrm{A} 1 \mathrm{~B} 2-\mathrm{X} 2$, hence $\mathrm{X} 2-$ ). During the PQ-X test, the subjects did as before and related $\mathrm{S}+$ with $\mathrm{S}+(\mathrm{P} 1 \mathrm{Q} 1-\mathrm{X} 1)$ and $\mathrm{S}-$ with $\mathrm{S}-(\mathrm{P} 1 \mathrm{Q} 2-\mathrm{X} 2)$. So conceptualized, the procedures led to the formation of two classes of discriminative $\mathrm{AB}, \mathrm{PQ}$ and $\mathrm{X}$ stimuli.

This account, hereafter referred to as the 'matching same functions account', was supported by a recent study by Carpentier et al. (2002b). After being trained on simple $\mathrm{A}$ and $\mathrm{B}$ discriminations $(\mathrm{A} 1+/ \mathrm{A} 2-, \mathrm{B} 1+/ \mathrm{B} 2-)$, the subsequent $\mathrm{J}_{-}$ A training (J1-A1, $\mathbf{J} 2-\mathrm{A} 2)$ produced similar $\mathbf{J}-\mathrm{B}$ performances $(\mathrm{J} 1-\mathrm{B} 1, \mathrm{~J} 2-\mathrm{B} 2)$. Likewise, after being trained on conditional $\mathrm{D}-\mathrm{E}$ and $\mathrm{F}-\mathrm{G}$ conditional discriminations (D1-E1, D2-E2, F1-G1, F2-G2), subsequent XD-E training (X1D1-E1, X1D2-E2, X2D1-E2, X2D2-E1) produced consistent $\mathrm{XF}-\mathrm{G}$ performances (e.g. $\mathrm{X} 1 \mathrm{~F} 1-\mathrm{G} 1, \mathrm{X} 2 \mathrm{~F} 1-\mathrm{G} 2$ ). Additional tests indicated that the conditional $\mathrm{J}$ and contextual $\mathrm{X}$ stimuli were functionally substitutable for one another (J1D1-E1, J2D1-E2, J1D2-E2, $\mathrm{J} 2 \mathrm{E} 2-\mathrm{D} 1 ; \mathrm{X} 1-\mathrm{A} 1, \mathrm{X} 2-\mathrm{A} 2)$ and had the same discriminative functions $(\mathrm{J} 1+/ \mathrm{J} 2-, \mathrm{X} 1+/ \mathrm{X} 2-)$. In fact, when given tests with newly introduced $\mathrm{C}$ stimuli as samples and as comparisons and the $\mathrm{A}$ and $\mathrm{X}$ stimuli as contextual stimuli $(\mathrm{AC}-\mathrm{C}, \mathrm{XC}-$ $\mathrm{C})$, most subjects demonstrated identity matching (presumably $\mathrm{S}+$ configurations) when given $\mathrm{A} 1+$ and $\mathrm{X} 1+$, and oddity matching (presumably $\mathrm{S}-$ configurations) when given $\mathrm{A} 2-$ and $\mathrm{X} 2-$. Collectively, these findings indicated that the subjects matched stimuli with any other stimuli of same discriminative functions.

The present study examined if the generalized matching of stimuli with same discriminative functions could be related to the training and/or testing order. Perhaps, these performances resulted from the fact that the lower-order tasks were trained before the higher-order tasks: the threeterm contingency tasks $(\mathrm{A} 1+/ \mathrm{A} 2-, \mathrm{B} 1+/ \mathrm{B} 2-)$ before the four-term contingency tasks $(\mathrm{J}-\mathrm{A})$, and the four-term contingency tasks (D-E, F-G) before the five-term contingency tasks (XD-E). 
Kennedy and Laitinen (1988) reported that unless $\mathrm{A}-\mathrm{B}, \mathrm{A}-\mathrm{C}$, and $\mathrm{A}-\mathrm{D}$ performances were trained before these tasks were brought under contextual control (XA-B, XA-C, XA-D), contextual control over transitivity relations (XB-C, XD-C, XD-B) did not emerge.

Matching on the basis of same discriminative functions could also have been facilitated by fact that the less complex $\mathbf{J}-\mathbf{B}$ tests were presented before the more complex and presumably more difficult $\mathrm{XF}-\mathrm{G}$ test. Studies by Adams et al. (1993), Fields et al. (2000), Sidman et al. (1985) have shown that complex performances can be enhanced by the prior introduction of easier and/ or prerequisite test performances. Thus it remains to be seen if the transfer from XD-E to XF-G also occurs when tested before the transfer from $\mathbf{J}-\mathbf{A}$ to $\mathbf{J}-\mathbf{B}$ is measured.

The current study consisted of two experiments. In both experiments, the subjects were trained on $\mathrm{A}$ and $\mathrm{B}$ discrimination tasks and on $\mathrm{J}-\mathrm{A}$ matching tasks, and transfer from $\mathrm{J}-\mathrm{A}$ to $\mathrm{J}-\mathrm{B}$ was assessed. Furthermore, the subjects received training on $\mathrm{D}-\mathrm{E}, \mathrm{F}-\mathrm{G}$, and $\mathrm{XD}-\mathrm{E}$ matching tasks, and transfer from $\mathrm{XD}-\mathrm{E}$ to $\mathrm{XF}-\mathrm{G}$ was assessed (for a schematic overview of these tasks, see Table 1). Finally, they received additional tests (not shown in Table 1) in which the discriminative properties of the $\mathrm{J}$ and $\mathrm{X}$ stimuli, and matching on the basis of same discriminative functions of newly introduced stimuli were measured (e.g. X1+/X2, XH-H, X-words). The experiments differed with regard to the order in which the training tasks were presented. In Experiment 1, the lower-order contingency tasks were trained first: $\mathrm{A} 1+/ \mathrm{A} 2-$ and $\mathrm{B} 1+/ \mathrm{B} 2-$ before $\mathrm{J}-\mathrm{A}$, and $\mathrm{D}-\mathrm{E}$ and $\mathrm{F}-\mathrm{G}$ before XD-E. In Experiment 2, the higher-order contingency tasks were trained first: $\mathrm{J}-\mathrm{A}$ before $\mathrm{A} 1+$ / $\mathrm{A} 2-$ and $\mathrm{B} 1+/ \mathrm{B} 2-$, and $\mathrm{XD}-\mathrm{E}$ before $\mathrm{D}-\mathrm{E}$ and $\mathrm{F}-\mathrm{G}$. Each experiment consisted of two conditions. The conditions differed with regard to the order in which the initial transfer tests were presented. In Condition A, transfer across conditional discrimination tasks (from $\mathbf{J}-\mathbf{A}$ to $\mathbf{J}-\mathbf{B}$ ) was tested before the transfer across contextually controlled discrimination tasks (from XD-E to $\mathrm{XF}-\mathrm{G})$. In Condition B, this testing sequence was reversed. Condition A of Experiment 1 involved the same sequential arrangement as the Carpentier et al. (2002b) study. Would this condition be superior to all other conditions? If not, would similar transfer findings be observed in Condition $\mathrm{B}$ of that experiment and not in Experiment 2 (training order effect), or in Condition A of Experiment 2 but not in any of the B conditions (test order effect)?

\section{Experiment 1}

This experiment examined test order effects when the lower-order contingency tasks are trained before the higher-order contingency tasks. Would the transfer of discriminative functions and

Table 1

Order of training tasks and of initial transfer tests

\begin{tabular}{llllll}
\hline Training test & \multicolumn{2}{l}{ Experiment 1} & & Experiment 2 \\
\cline { 2 - 3 } \cline { 5 - 5 } & Condition A & Condition B & & Condition A & Condition B \\
\hline Train & $\mathrm{A} 1+/ \mathrm{A} 2-$ & $\mathrm{D}-\mathrm{E}$ & $\mathrm{J}-\mathrm{A}$ & $\mathrm{XD}-\mathrm{E}$ \\
Train & $\mathrm{B} 1+/ \mathrm{B} 2-$ & $\mathrm{F}-\mathrm{G}$ & $\mathrm{A} 1+/ \mathrm{A} 2-$ & $\mathrm{D}-\mathrm{E}$ \\
Test & $\mathrm{J}-\mathrm{A}$ & $\mathrm{XD}-\mathrm{E}$ & $\mathrm{B} 1+/ \mathrm{B} 2-$ & $\mathrm{F}-\mathrm{G}$ \\
Train & $\mathrm{J}-\mathrm{B}$ & $\mathrm{XF}-\mathrm{G}$ & $\mathrm{J}-\mathrm{B}-\mathrm{G}$ & $\mathrm{J}-\mathrm{A}$ \\
Train & $\mathrm{D}-\mathrm{E}$ & $\mathrm{A} 1+/ \mathrm{A} 2-$ & $\mathrm{XD}-\mathrm{E}$ & $\mathrm{A} 1+/ \mathrm{A} 2-$ \\
Test & $\mathrm{F}-\mathrm{G}$ & $\mathrm{B} 1+/ \mathrm{B} 2-$ & $\mathrm{D}-\mathrm{E}$ & $\mathrm{B} 1+/ \mathrm{B} 2-$ \\
\hline
\end{tabular}


matching on the basis of these functions be more evident in Condition A (testing $\mathrm{J}-\mathrm{B}$ before $\mathrm{XF}-\mathrm{G}$ ) than in Condition $\mathrm{B}$ (testing $\mathrm{XF}-\mathrm{G}$ before $\mathrm{J}-\mathrm{B}$ )?

\subsection{Method}

\subsubsection{Subjects}

Six subjects, two males and four females, participated. Their ages ranged from 19 to 26 years. Two subjects (1 and 6) were psychology students and four non-psychology students $(2,3,4$, and 5). All students were recruited through a bulletin board announcement. None of them had any prior experience with stimulus control related research. Following the completion of the experiment, the participants were fully debriefed, and paid for their participation. The sessions were arranged such that participants did not meet with one another in the vicinity of the laboratory.

\subsubsection{Apparatus and materials}

The participants were seated at a table in a small experimental room containing an Apple Macintosh microcomputer (Performa 5200) which displayed black forms $(4 \times 4 \mathrm{~cm})$ on a white

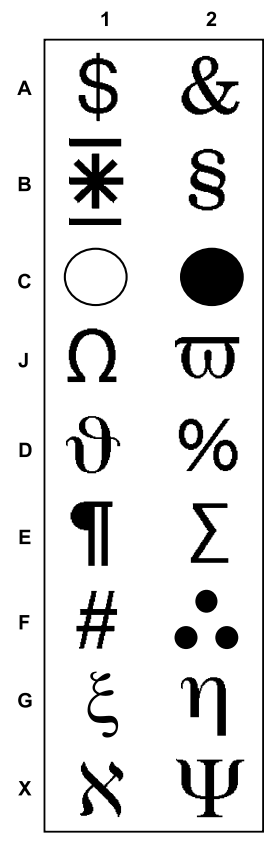

Fig. 1. Experimental stimuli. background (see Fig. 1). These stimuli are identified here by alphanumeric codes (e.g. A1, X2). Stimulus presentation and response recording were controlled by the computer application 'Psyscope' (Cohen et al., 1993).

\subsubsection{Sessions, tasks, and feedback}

The participants were exposed to the experimental conditions individually and completed the experiment in one session (93-133 min). Simple discrimination, conditional discrimination, and contextually controlled discrimination tasks were used. A simple discrimination trial started with the simultaneous presentation of two horizontally aligned stimuli near the bottom of the screen. The subjects were instructed to move the cursor to the selected comparison and then click the mouse. The locations of the correct and incorrect comparisons were counterbalanced over trials. The conditional discrimination trials were the same except that a third stimulus (sample) appeared at the center of the screen. The same applied to the contextually controlled conditional discriminations, except that a fourth stimulus (contextual cue) appeared $1 \mathrm{~cm}$ above the sample. All stimuli remained on display until responding had been completed.

During training, each response was followed by feedback on the screen ( $1 \mathrm{~s})$, 'RIGHT' after correct responses and 'WRONG' after incorrect responses. During testing, there were no programmed consequences. A 2-s interval (blank screen) separated all trials.

\subsubsection{Experimental sequence}

The program consisted of 17 phases (see Table 2). Phases 1-6 were designed to generate transfer of conditional control. In Phase 1, three simultaneous $\mathrm{A}, \mathrm{B}$, and $\mathrm{C}$ discriminations were trained. Then the A discriminations were brought under conditional control (training and testing $\mathrm{J}-\mathrm{A}$ ) in Phases 2 and 3. Finally, transfer from $\mathbf{J}-\mathbf{A}$ to $\mathbf{J}-\mathbf{B}$ was assessed in Phase 4. Subjects who failed the $J_{-}$ $\mathrm{B}$ test received a mixed $\mathbf{J}-\mathbf{A}$ and $\mathbf{J}-\mathbf{B}$ training in Phase 5 followed by a $\mathbf{J}-\mathrm{C}$ transfer test in Phase 6.

Phases 7-10 were directed at establishing transfer of contextual control. In Phases 7 and 8, two sets of conditional discriminations were trained: 
Table 2

Training and test sequence in Experiment 1

\begin{tabular}{|c|c|c|c|c|}
\hline Phases & Train/Test & Criterion & Tasks & \#Trials \\
\hline \multirow[t]{3}{*}{1} & \multirow[t]{3}{*}{ Train } & \multirow[t]{3}{*}{$23 / 24$} & $\mathrm{~A} 1+/ \mathrm{A} 2-$ & 8 \\
\hline & & & $\mathrm{B} 1+/ \mathrm{B} 2-$ & 8 \\
\hline & & & $\mathrm{C} 1+/ \mathrm{C} 2-$ & 8 \\
\hline \multirow[t]{4}{*}{2} & \multirow[t]{4}{*}{ Train } & \multirow[t]{4}{*}{$23 / 24$} & $\mathbf{J}-\mathbf{A}$ & 12 \\
\hline & & & $\mathrm{A} 1+/ \mathrm{A} 2-$ & 4 \\
\hline & & & $\mathrm{B} 1+/ \mathrm{B} 2-$ & 4 \\
\hline & & & $\mathrm{C} 1+/ \mathrm{C} 2-$ & 4 \\
\hline \multirow[t]{4}{*}{3} & \multirow[t]{4}{*}{ Test } & \multirow[t]{4}{*}{$23 / 24$} & $\mathrm{~J}-\mathrm{A}$ & 12 \\
\hline & & & $\mathrm{A} 1+/ \mathrm{A} 2-$ & 4 \\
\hline & & & $\mathrm{B} 1+/ \mathrm{B} 2-$ & 4 \\
\hline & & & $\mathrm{C} 1+/ \mathrm{C} 2-$ & 4 \\
\hline 4 & Test & $14 / 16$ & $\mathrm{~J}-\mathrm{B}$ & 16 \\
\hline \multirow[t]{5}{*}{5} & \multirow[t]{5}{*}{ Train } & \multirow[t]{5}{*}{$23 / 24$} & $\mathrm{~J}-\mathrm{B}$ & 12 \\
\hline & & & $\mathbf{J}-\mathbf{A}$ & 4 \\
\hline & & & $\mathrm{A} 1+/ \mathrm{A} 2-$ & 2 \\
\hline & & & $\mathrm{B} 1+/ \mathrm{B} 2-$ & 4 \\
\hline & & & $\mathrm{C} 1+/ \mathrm{C} 2-$ & 2 \\
\hline 6 & Test & $14 / 16$ & $\mathrm{~J}-\mathrm{C}$ & 16 \\
\hline 7 & Train & $15 / 16$ & $\mathrm{D}-\mathrm{E}$ & 16 \\
\hline \multirow[t]{2}{*}{8} & \multirow[t]{2}{*}{ Train } & \multirow[t]{2}{*}{$23 / 24$} & $\mathrm{~F}-\mathrm{G}$ & 16 \\
\hline & & & $\mathrm{D}-\mathrm{E}$ & 8 \\
\hline \multirow[t]{3}{*}{9} & \multirow{3}{*}{ Train } & \multirow{3}{*}{$23 / 24$} & $X D-E$ & 16 \\
\hline & & & $\mathrm{D}-\mathrm{E}$ & 4 \\
\hline & & & $\mathrm{F}-\mathrm{G}$ & 4 \\
\hline 10 & Test & $14 / 16$ & $\mathrm{XF}-\mathrm{G}$ & 16 \\
\hline \multirow[t]{3}{*}{11} & \multirow[t]{3}{*}{ Train } & \multirow[t]{3}{*}{$15 / 16$} & $\mathrm{~A} 1+/ \mathrm{A} 2-$ & 4 \\
\hline & & & $\mathrm{J}-\mathrm{A}$ & 4 \\
\hline & & & $X D-E$ & 4 \\
\hline 12 & Test & $14 / 16$ & $\mathrm{JD}-\mathrm{E}$ & 16 \\
\hline 13 & Test & $14 / 16$ & $\mathrm{X}-\mathrm{A}$ & 16 \\
\hline \multirow[t]{2}{*}{14} & \multirow[t]{2}{*}{ Test } & \multirow[t]{2}{*}{$14 / 16$} & $\mathrm{~J} 1+/ \mathrm{J} 2-$ & 8 \\
\hline & & & $\mathrm{X} 1+/ \mathrm{X} 2-$ & 8 \\
\hline \multirow[t]{3}{*}{15} & \multirow[t]{3}{*}{ Test } & \multirow[t]{3}{*}{$22 / 24$} & AH-H & 8 \\
\hline & & & JH-H & 8 \\
\hline & & & XH-H & 8 \\
\hline 16 & Test & $44 / 48$ & A-words & 16 \\
\hline & & & J-words & 16 \\
\hline & & & X-words & 16 \\
\hline 17 & Test & $28 / 32$ & word-word & 32 \\
\hline
\end{tabular}

$\mathrm{D}-\mathrm{E}$ and $\mathrm{F}-\mathrm{G}$. After bringing $\mathrm{D}-\mathrm{E}$ under contextual control in Phase 9 (XD-E), transfer from $\mathrm{XD}-\mathrm{E}$ to $\mathrm{XF}-\mathrm{G}$ was assessed in Phase 10.

Phases 11-17 were designed to demonstrate the discriminative properties of critical stimuli, and to test additional matching performances consistent with the 'matching same functions' account. Following a review training (Phase 11), a series of tests was initiated. These tests assessed the interchange- ability of the discriminative A stimuli, the conditional $\mathbf{J}$ stimuli, and contextual $\mathrm{X}$ stimuli (Phases 12 and 13), the discriminative properties of the $\mathrm{J}$ and X stimuli (Phase 14), and the matching of A, J, and $\mathrm{X}$ stimuli with newly introduced stimulus configurations of same discriminative properties (Phases 15-17).

All subjects received the above program. Subjects 1-3 received Phases 1-6 before Phases 7-10 (Condition A). Subjects 4-6 received Phases 7-10 before Phases 1-6 (Condition B). All subjects received Phases 11-17 last. The criteria for demonstrated competence were N-1 trials correct for all trained performances and $\mathrm{N}-2$ trials correct for all derived performances.

\subsubsection{Phase 1: training simple $A, B, C$ discriminations}

Immediately before the presentation of the first trial, the following instruction appeared on the screen: "Start the program by pressing any one key. You will then see two forms. Choose a form by clicking it with the mouse." Blocks of 24 trials were used, eight $\mathrm{A} 1+/ \mathrm{A} 2-$ trials randomly mixed with eight $\mathrm{B} 1+/ \mathrm{B} 2-$, and eight $\mathrm{C} 1+/ \mathrm{C} 2-$ trials. Subjects who demonstrated criterion performance (see Table 2) proceeded to Phase 2.

\subsubsection{Phases 2 and 3: training and testing $J-A$}

These two phases were directed at bringing the A discriminations under conditional control and, by doing so, inducing transfer of discriminative functions from A to $\mathbf{J}$ (De Rose et al., 1988; Smeets, 1994). The $\mathrm{J}-\mathrm{A}$ relations were trained in Phase 2. This phase started with the following instruction on the screen: "Now you will also see a form at the center of the screen. Look at that form before selecting any of the forms below." Blocks of 24 trials were used: six $\mathrm{J} 1-\mathrm{A} 1$ and six $\mathrm{J} 2-\mathrm{A} 2$ trials randomly mixed with 12 simple $\mathrm{A}, \mathrm{B}$, and $\mathrm{C}$ discrimination trials. Subjects who demonstrated criterion performance proceeded to Phase 3. This phase assessed whether the trained simple and conditional discrimination tasks remained intact under testing conditions. Immediately before the first trial, the following instruction appeared on the screen: "Now you will no longer see whether your selections are right or wrong. Do your best." 
Subjects who passed the test proceeded to Phase 4 . Those who failed the test, returned to Phase 2 before receiving Phase 3 again.

\subsubsection{Phase 4: testing $J-B$}

This test assessed transfer from $\mathbf{J}-\mathbf{A}$ to $\mathbf{J}-\mathbf{B}$. If the $\mathbf{J}-\mathbf{A}$ training had induced transfer from $\mathrm{A}$ to $\mathbf{J}$ $(\mathrm{J} 1+/ \mathrm{J} 2-)$, the subjects could have matched on the basis of same discriminative functions, $\mathrm{J} 1+$ with $\mathrm{A} 1+$, and $\mathrm{J} 2$ - with $\mathrm{A} 2-$. If so, the subjects would be expected to do the same during the $\mathrm{J}-\mathrm{B}$ test and relate $\mathrm{J} 1+$ with $\mathrm{B} 1+$, and $\mathrm{J} 2$ - with $\mathrm{B} 2-$. Blocks of 16 trials were used, eight $\mathrm{J} 1-\mathrm{B} 1$ trials mixed with eight J2-B2 trials. Subjects who passed the $\mathbf{J}-\mathbf{B}$ test proceeded to Phase 7 . Those who failed this test returned to Phase 2, before receiving Phase 4 again. Subjects who also failed the second presentation of the $\mathbf{J}-\mathbf{B}$ test proceeded to Phases 5 and 6.

\subsubsection{Phases 5 and 6: training $J-B$ and $J-A$, and testing $\mathrm{J}-\mathrm{C}$}

The failure to demonstrate $\mathrm{J}-\mathrm{B}$ (Phase 4) could have resulted from some form of interfering stimulus control. If so, this problem might be remedied by training the subjects to relate the $\mathbf{J}$ stimuli to multiple stimuli with same discriminative functions: Mixed $\mathbf{J}-\mathrm{A}$ and $\mathrm{J}-\mathrm{B}$ training (Phase 5). Subsequently, the subjects might more likely relate $\mathrm{J} 1+$ to $\mathrm{C} 1+$ and $\mathrm{J} 2-$ to $\mathrm{C} 2-$ in Phase 6.

In Phase 5, each training block consisted of 12 $\mathbf{J}-\mathrm{B}$ trials mixed with four $\mathbf{J}-\mathrm{A}$ and eight $(\mathrm{A}, \mathrm{B}, \mathrm{C})$ simple discrimination trials. Subjects who demonstrated criterion performance proceeded to Phase 6 in which transfer from $\mathbf{J}-\mathbf{A}$ and $\mathbf{J}-\mathbf{B}$ to $\mathbf{J}-\mathrm{C}$ was assessed (block of $16 \mathrm{~J}-\mathrm{C}$ test trials). Subjects who passed this test proceeded to Phase 7. Subjects who failed the test returned to Phase 5 before receiving Phase 6 again. At that point, subjects proceeded, irrespective of their test performance, to Phase 7 (Subjects 1-3) or to Phase 11 (Subjects 4-6).

\subsubsection{Phases 7 and 8: training $D-E$ and $F-G$}

Two sets of conditional discriminations were trained: D1-E1, D2-E2 in Phase 7 and F1-G1, F2-G2 (mixed with D-E trials) in Phase 8. This training permitted the formation of eight discri- minative compounds: D1E1 +, D1E2-, D2E2+, $\mathrm{D} 2 \mathrm{E} 1-, \mathrm{F} 1 \mathrm{G} 1+, \mathrm{F} 1 \mathrm{G} 2-, \mathrm{F} 2 \mathrm{G} 2+, \mathrm{F} 2 \mathrm{G} 1-$. The procedures were the same as for the $\mathrm{J}-\mathrm{A}$ training (Phase 2). Subjects who demonstrated criterion performance in each phase proceeded to Phase 9.

\subsubsection{Phase 9: training $X D-E$}

This phase was directed at inducing transfer of discriminative properties from DE to $\mathrm{X}$. This was achieved by bringing the correct D1-E1 and D2$\mathrm{E} 2$ relations under control of stimulus $\mathrm{X} 1$, and the incorrect D1-E2 and D2-E1 relations under control of stimulus X2. Each training block consisted of $16 \mathrm{XD}-\mathrm{E}$ trials (four X1D1-E1, four X1D2-E2, four X2D1-E2, and four $\mathrm{X} 2 \mathrm{D} 2-\mathrm{E} 1$ trials) mixed with four $\mathrm{D}-\mathrm{E}$ and four $\mathrm{F}-\mathrm{G}$ trials. Subjects who demonstrated criterion performance proceeded to Phase 10.

\subsubsection{Phase 10: testing $X F-G$}

This phase assessed transfer of control across sample-comparison relations with same discriminative properties, from $\mathrm{XD}-\mathrm{E}$ to $\mathrm{XF}-\mathrm{G}$. If the $\mathrm{XD}-\mathrm{E}$ training (Phase 9) had induced transfer of discriminative functions from $\mathrm{DE}$ to $\mathrm{X}(\mathrm{X} 1+$, $\mathrm{X} 2-)$, the subjects had matched stimuli with same discriminative functions, $\mathrm{X} 1+$ with $\mathrm{D} 1 \mathrm{E} 1+$ and $\mathrm{D} 2 \mathrm{E} 2+$, and $\mathrm{X} 2-$ with D1E2 - and D2E1 - . If so, the same functional performance would be expected during the $\mathrm{XF}-\mathrm{G}$ trials (e.g. matching $\mathrm{X} 1+$ with $\mathrm{F} 1 \mathrm{G} 1+$, and $\mathrm{X} 2-$ with $\mathrm{F} 1 \mathrm{G} 2-$ ). Sixteen test trials were used: four X1F1-G1 trials randomly mixed with four X1F2-G2, four $\mathrm{X} 2 \mathrm{~F} 1-\mathrm{G} 2$ and four $\mathrm{X} 2 \mathrm{~F} 2-\mathrm{G} 1$ trials. Subjects who passed the test proceeded to Phase 11 (Subjects $1-3$ ) or to Phase 1 (Subjects 4-6). Those who failed this test returned to Phase 9 (training XDE) before receiving Phase 10 again.

\subsubsection{Phase 11: review training}

This training was designed to ensure that all prerequisite performances were intact before the following tests were introduced (see below). Blocks of 16 trials were used: four A1+/A2 - trials mixed with four $\mathrm{J}-\mathrm{A}$, four $\mathrm{D}-\mathrm{E}$, and four XD-E trials. Subjects who demonstrated criterion performance proceeded to Phase 12 or 13, whichever came first. Subjects 1, 3, and 4 received Phase 12 before Phase 
Table 3

Tested word-word relations

\begin{tabular}{|c|c|c|c|c|c|c|c|c|c|}
\hline \multicolumn{2}{|c|}{ Comparisons } & \multicolumn{8}{|c|}{ Samples } \\
\hline & & Polite & Rude & Healthy & Sick & Intact & Broken & $2+2=4$ & $2+2=3$ \\
\hline Polite & Rude & & & & & $\times$ & $x$ & $\times$ & $x$ \\
\hline Healthy & Sick & $x$ & $x$ & & & $\times$ & $x$ & & \\
\hline Intact & Broken & & & $\times$ & $\times$ & & & $x$ & $\times$ \\
\hline $2+2=4$ & $2+2=3$ & $x$ & $x$ & $\times$ & $\times$ & & & & \\
\hline
\end{tabular}

Each sample-comparison relation (e.g. Intact-Polite) was tested twice.

13; Subjects 2, 5, and 6 received Phase 13 before Phase 12.

\subsubsection{Phases 12 and 13: testing $J D-E$ and $X-A$}

These tests assessed the substitutability of the conditional $\mathbf{J}$ and contextual $\mathrm{X}$ stimuli of same discriminative functions. Phase 12 tested whether the $\mathrm{J}$ stimuli replaced the $\mathrm{X}$ stimuli (transfer from $\mathrm{XD}-\mathrm{E}$ to JD-E). The test consisted of 16 trials: four J1D1-E1 trials randomly mixed with four J1D2-E2, four J2D1-E2, and four J2D2-E1 trials. This test, and all following tests, were presented twice, each time followed by a review training.

Phase 13 assessed whether the $\mathrm{X}$ stimuli replaced the $\mathbf{J}$ stimuli (transfer from $\mathbf{J}-\mathrm{A}$ to $\mathrm{X}-\mathrm{A}$ ). The test consisted of 16 trials: eight X1-A1 trials randomly mixed with eight $\mathrm{X} 2-\mathrm{A} 2$ trials.

\subsubsection{Phase 14: testing $J 1+\mid J 2-$ and $X 1+\mid X 2-$}

This phase tested discriminative functions of the $\mathbf{J}$ and $\mathrm{X}$ stimuli in the context of a simple discrimination task. The test consisted of 16 trials: eight $\mathrm{J} 1+/ \mathrm{J} 2-$ trials randomly mixed with eight $\mathrm{X} 1+/ \mathrm{X} 2-$ trials.

\subsubsection{Phase 15: testing AH-H, JH-H, \& XH-H}

This phase assessed whether matching on the basis of common discriminative functions would also be evident in the context of identity match-tosample tasks with newly introduced $\mathrm{H}$ stimuli (e.g. $\mathrm{XH}-\mathrm{H})$. The rationale for these tests was as follows: when given identity matching probes, most humans relate, without experimental training, samples to same comparisons, probably because they learned to do so in the past. Thus, identity tasks are seen as $\mathbf{S}+$ configurations and oddity tasks as $\mathrm{S}-$ configurations. Hence, our subjects would be expected to show identity matching when given $\mathrm{A} 1, \mathrm{~J} 1$, or $\mathrm{X} 1$, and oddity matching when given $\mathrm{A} 2, \mathrm{~J} 2$, or $\mathrm{X} 2$.

\subsubsection{Phase 16: testing A-words, J-words, $X$ - words}

This test assessed whether the subjects matched the A, J, and X stimuli also with printed words of presumably same discriminative properties. The test consisted of 48 trials with the A, J, or X stimuli as samples, and with POLITE and RUDE (12 trials), HEALTHY and SICK (12 trials), INTACT and BROKEN ( 12 trials), or $2+2=4$ and $2+2=$ 3 (12 trials) as comparisons. The rationale was the same as before. If the subjects had been matching stimuli on the basis of same discriminative functions, they would be expected to do so again and relate $\mathrm{A} 1+, \mathrm{J} 1+$, and $\mathrm{X} 1+$ to POLITE, HEALTHY, INTACT, $2+2=4$, and A $2-, \mathrm{J} 2-$ , and X $2-$ to RUDE, SICK, BROKEN, $2+2=3$.

\subsubsection{Phase 17: testing word-word}

This test assessed if failures to pass the previous test (e.g. A1-POLITE, A2-RUDE) could be related to some of the words not having the assumed discriminative properties (Barnes-Holmes et al., 2000). In this test, therefore, subjects were given the opportunity to match printed words with presumably same discriminative functions. The test consisted of 32 trials (see Table 3): $16(\mathrm{~S}+$ )$(\mathrm{S}+)$ matching trials (e.g. POLITE-HEALTHY), randomly mixed with $16(\mathrm{~S}-)-(\mathrm{S}-)$ matching trials (RUDE-SICK). 


\subsection{Results and discussion}

Training of the $\mathrm{A}, \mathrm{B}$, and $\mathrm{C}$ simple discrimination tasks and the $\mathrm{J}-\mathrm{A}$ conditional discrimination tasks required $76-120$ trials in Subjects $1-3$, and $72-96$ trials in Subjects 4-6. Training of the D-E, $\mathrm{F}-\mathrm{G}$, and $\mathrm{XD}-\mathrm{E}$ tasks required $88-128$ trials in Subjects $1-3$ and $4-6$.

The test data are shown in Table 4. Four Subjects $(3,4,5$, and 6) responded with (near) perfect accuracy during all tests. The same applied to Subject 1 except that she appeared to ignore the $\mathbf{J}$ stimuli when used as contextual stimuli in identity matching tasks (JH-H). Likewise, Subject 2 did not respond to the $\mathrm{J}$ stimuli when used together with the trained discriminative $\mathrm{B}$ and $\mathrm{C}$ stimuli and with the trained D-E relations. This continued until she received the opportunity to respond differentially to $\mathrm{J} 1$ and $\mathrm{J} 2(\mathrm{~J} 1+/ \mathrm{J} 2-)$. From that point on, her test performance was indistinguishable from that of the other five subjects and she consistently matched on the basis of same discriminative functions.

In brief, in both conditions, the test performances were highly consistent with those obtained in previous research (Carpentier et al., 2002b). Thus, the outcome of that study was not related to the order in which the initial matching probes were presented (i.e. the less complex $\mathbf{J}-\mathbf{B}$ test before the more complex $\mathrm{XF}-\mathrm{G}$ test).

Table 4

Percentages of correct test responses

\begin{tabular}{|c|c|c|c|c|c|c|c|c|c|c|c|c|c|}
\hline \multirow[b]{3}{*}{ Tests } & \multirow[b]{3}{*}{ Presentations } & \multicolumn{6}{|c|}{ Subjects Experiment 1} & \multicolumn{6}{|c|}{ Subjects Experiment 2} \\
\hline & & \multicolumn{3}{|c|}{ Condition A } & \multicolumn{3}{|c|}{ Condition B } & \multicolumn{3}{|c|}{ Condition A } & \multicolumn{3}{|c|}{ Condition B } \\
\hline & & 1 & 2 & 3 & 4 & 5 & 6 & 7 & 8 & 9 & 10 & 11 & 12 \\
\hline \multirow[t]{2}{*}{$\mathrm{J}-\mathrm{B}$} & 1 & 94 & 50 & 94 & 94 & 100 & 100 & 0 & 100 & 100 & 50 & 0 & 100 \\
\hline & 2 & & 50 & & & & & 0 & & & 100 & 0 & \\
\hline \multirow[t]{2}{*}{$\mathrm{J}-\mathrm{C}$} & 1 & & 50 & & & & & 94 & & & & 100 & \\
\hline & 2 & & 50 & & & & & & & & & & \\
\hline \multirow[t]{2}{*}{$\mathrm{XF}-\mathrm{G}$} & 1 & 100 & 100 & 94 & 100 & 100 & 88 & 50 & 63 & 63 & 56 & 75 & 100 \\
\hline & 2 & & & & & & & 50 & 100 & 100 & 50 & 94 & \\
\hline \multirow[t]{2}{*}{$\mathrm{JD}-\mathrm{E}$} & 1 & 100 & 50 & 100 & 100 & 100 & 82 & 82 & 75 & 100 & 44 & 100 & 94 \\
\hline & 2 & 94 & 50 & 100 & 100 & 100 & 100 & 94 & 75 & 100 & 50 & 13 & 100 \\
\hline \multirow[t]{2}{*}{$\mathrm{X}-\mathrm{A}$} & 1 & 100 & 100 & 100 & 100 & 100 & 100 & 100 & 100 & 100 & 100 & 100 & 100 \\
\hline & 2 & 100 & 100 & 100 & 100 & 100 & 100 & 100 & 100 & 100 & 0 & 100 & 100 \\
\hline $\mathrm{J} 1+/ \mathrm{J} 2-$ & 1 & 100 & 88 & 100 & 100 & 100 & 100 & 0 & 100 & 100 & 100 & 13 & 100 \\
\hline $\mathrm{X} 1+/ \mathrm{X} 2-$ & 1 & 100 & 63 & 100 & 100 & 100 & 100 & 0 & 0 & 100 & 0 & 100 & 100 \\
\hline $\mathrm{J} 1+/ \mathrm{J} 2-$ & 2 & 100 & 100 & 100 & 100 & 100 & 100 & 0 & 100 & 100 & 100 & 0 & 100 \\
\hline $\mathrm{X} 1+/ \mathrm{X} 2-$ & 2 & 100 & 100 & 100 & 100 & 100 & 100 & 0 & 0 & 100 & 0 & 100 & 100 \\
\hline AH-H & 1 & 100 & 100 & 100 & 100 & 100 & 100 & 50 & 38 & 100 & 50 & 50 & 100 \\
\hline JH-H & 1 & 50 & 100 & 100 & 100 & 100 & 100 & 63 & 38 & 75 & 13 & 0 & 100 \\
\hline XH-H & 1 & 100 & 100 & 100 & 100 & 88 & 75 & 50 & 63 & 88 & 63 & 50 & 100 \\
\hline AH-H & 2 & 100 & 100 & 88 & 100 & 100 & 100 & 50 & 88 & 88 & 50 & 50 & 100 \\
\hline JH-H & 2 & 50 & 100 & 100 & 100 & 88 & 100 & 50 & 75 & 100 & 38 & 50 & 100 \\
\hline XH-H & 2 & 100 & 100 & 88 & 100 & 100 & 100 & 50 & 38 & 100 & 63 & 63 & 100 \\
\hline A-words & 1 & 100 & 94 & 88 & 100 & 100 & 88 & 38 & 94 & 100 & 50 & 50 & 100 \\
\hline J-words & 1 & 88 & 100 & 100 & 100 & 94 & 100 & 50 & 100 & 100 & 50 & 50 & 100 \\
\hline X-words & 1 & 100 & 100 & 100 & 100 & 100 & 100 & 13 & 0 & 100 & 50 & 56 & 100 \\
\hline A-words & 2 & 94 & 100 & 100 & 100 & 100 & 94 & 56 & 94 & 100 & 6 & 50 & 100 \\
\hline J-words & 2 & 94 & 100 & 100 & 100 & 94 & 94 & 56 & 100 & 100 & 44 & 56 & 100 \\
\hline X-words & 2 & 100 & 100 & 100 & 100 & 94 & 100 & 13 & 0 & 100 & 19 & 63 & 100 \\
\hline \multirow[t]{2}{*}{ word-word } & 1 & 97 & 100 & 97 & 91 & 100 & 100 & 97 & 100 & 100 & 97 & 97 & 97 \\
\hline & 2 & 97 & 94 & 97 & 97 & 100 & 100 & 100 & 97 & 97 & 100 & 100 & 100 \\
\hline
\end{tabular}

The order of the tests are as indicated except that in the B sequence of each experiment. $\mathrm{XF}-\mathrm{G}$ was tested before $\mathbf{J}-\mathrm{B}$ (and $\mathbf{J}-\mathrm{C}$ ). 


\section{Experiment 2}

This experiment examined test order effects when the higher-order contingency tasks are trained before the lower-order contingency tasks. Would the test results in Conditions A and B be similar to those obtained in Experiment 1?

\subsection{Method}

Six new subjects, two males and four females participated. Their ages ranged from 18 to 26 years. Two subjects were psychology students (7, 10) and four non-psychology students $(8,9,11$, 12). All subjects completed the experiment in one session (113-160 min).

The setting, stimuli, procedures, and number of phases were the same as in Experiment 1, except that the training order had been reversed (see Table 5). In Phases 1-6, J-A was trained before $\mathrm{A} 1+/ \mathrm{A} 2-$ and $\mathrm{B} 1+/ \mathrm{B} 2-$, and $\mathrm{J}-\mathrm{A}$ and $\mathrm{J}-\mathrm{B}$ were trained together with rather than after training $\mathrm{C} 1+/ \mathrm{C} 2-$. Likewise, in Phases $7-10$,
XD-E was trained before rather than after D-E and $\mathrm{F}-\mathrm{G}$. Subjects $7-9$ received Phases $1-6$ before Phases 7-10 (Condition A). Subjects 10-12 received Phases 7-10 before Phases 1-6 (Condition B). After having completed the first ten phases, all subjects proceeded to Phases 11-17 (same as in Experiment 1).

\subsection{Results and discussion}

Training of the $\mathrm{J}-\mathrm{A}$, and the $\mathrm{A}$ and $\mathrm{B}$ discrimination tasks required $32-48$ trials for Subjects 7-9, and 48-64 trials for Subjects 10-12. Training the $\mathrm{XD}-\mathrm{E}, \mathrm{D}-\mathrm{E}$ and $\mathrm{F}-\mathrm{G}$ tasks required $88-168$ trials for Subjects 7-9 and 136-184 trials for Subjects 10-12.

All subjects passed the $\mathbf{J}-\mathbf{B}$ test $(8,9,10,12)$ or the $\mathbf{J}-\mathrm{C}$ test $(7,11)$ (see Table 4$)$. Four subjects, two from Condition $\mathrm{A}(8,9)$ and two from Condition B $(11,12)$, also passed the XF-G test. From that point on, only Subjects 9 (Condition A) and 12 (Condition B) responded according to 'matching same functions' account. The other

Table 5

Training and test sequence in Experiment 2

\begin{tabular}{|c|c|c|c|c|}
\hline Phases & Train/test & Criterion & Tasks & \#Trials \\
\hline 1 & Train & $15 / 16$ & $\mathrm{~J}-\mathrm{A}$ & 16 \\
\hline \multirow[t]{3}{*}{2} & Train & $15 / 16$ & $\mathrm{~J}-\mathrm{A}$ & 8 \\
\hline & & & $\mathrm{A} 1+/ \mathrm{A} 2-$ & 4 \\
\hline & & & $\mathrm{B} 1+/ \mathrm{B} 2-$ & 4 \\
\hline \multirow[t]{3}{*}{3} & Test & $15 / 16$ & $\mathrm{~J}-\mathrm{A}$ & 8 \\
\hline & & & $\mathrm{A} 1+/ \mathrm{A} 2-$ & 4 \\
\hline & & & $\mathrm{B} 1+/ \mathrm{B} 2-$ & 4 \\
\hline 4 & Test & $14 / 16$ & $\mathrm{~J}-\mathrm{B}$ & 16 \\
\hline \multirow[t]{5}{*}{5} & Train & $23 / 24$ & $\mathrm{~J}-\mathrm{A}$ & 4 \\
\hline & & & $\mathrm{J}-\mathrm{B}$ & 8 \\
\hline & & & $\mathrm{A} 1+/ \mathrm{A} 2-$ & 4 \\
\hline & & & $\mathrm{B} 1+/ \mathrm{B} 2-$ & 4 \\
\hline & & & $\mathrm{C} 1+/ \mathrm{C}_{2}-$ & 4 \\
\hline 6 & Test & $14 / 16$ & $\mathrm{~J}-\mathrm{C}$ & 16 \\
\hline 7 & Train & $15 / 16$ & $X D-E$ & 16 \\
\hline \multirow[t]{2}{*}{8} & Train & $23 / 24$ & $\mathrm{D}-\mathrm{E}$ & 12 \\
\hline & & & $\mathrm{F}-\mathrm{G}$ & 12 \\
\hline \multirow[t]{3}{*}{9} & Train & $23 / 24$ & $X D-E$ & 16 \\
\hline & & & $\mathrm{D}-\mathrm{E}$ & 4 \\
\hline & & & $\mathrm{F}-\mathrm{G}$ & 4 \\
\hline 10 & Test & $14 / 16$ & $\mathrm{XF}-\mathrm{G}$ & 16 \\
\hline $11-17$ & Same as in Experiment 1 & & & \\
\hline
\end{tabular}


four subjects frequently selected the designated $\mathrm{S}$ - stimuli during the simple $\mathrm{J}$ and $\mathrm{X}$ discrimination probes (e.g. $\mathbf{J} 2+/ \mathrm{J} 1-$ ), and treated conditional discrimination tasks (e.g. A-words) as simple discrimination tasks (i.e. almost always selected POLITE, HEALTHY, INTACT, and $2+2=4)$ and the contextual conditional discrimination probes (e.g. JD-E and $\mathrm{AH}-\mathrm{H}$ ) as conditional discrimination tasks (D-E, H-H).

Thus again, transfer was not affected by the test order. The numbers of subjects passing the $\mathbf{J}-\mathrm{B}$ (or $\mathrm{J}-\mathrm{C})$ and $\mathrm{XF}-\mathrm{G}$ tests were about the same irrespective of which test was presented first. Transfer, however, was seriously affected by the training order. In Experiment 1, in which the lower-order contingency tasks were trained first, 5/ 6 subjects $(83 \%)$ passed all or all minus 1 transfer tests (overall: 97\%). Even the 'failing' subject passed 10/13 tests (77\%). By contrast, in Experiment 2 in which the higher-order contingency tasks were trained first, only $2 / 6$ subjects $(33 \%)$ passed all or all minus 1 tests. The other four subjects only passed $17-58 \%$ of the tests $(P=$ 0.046, Mann-Whitney).

The discrepancy between Experiments 1 and 2 is even more pronounced when not taking the $\mathrm{J}-\mathrm{B} /$ $\mathrm{J}-\mathrm{C}, \mathrm{XF}-\mathrm{G}$, and JD-E transfer performances of Subjects 7, 8, 10, and 11 at face value. Given that these four subjects systematically selected the designated $\mathrm{S}-$ stimuli during the $\mathrm{J}$ and/or $\mathrm{X}$ discrimination probes $(\mathrm{J} 1-/ \mathrm{J} 2+, \mathrm{X} 1-/ \mathrm{X} 2+)$, it should be assumed that the $\mathrm{J}-\mathrm{A}$ and $\mathrm{XD}-\mathrm{E}$ training had not induced transfer from $\mathrm{A}$ to $\mathrm{J}$ and from $\mathrm{D}-\mathrm{E}$ to $\mathrm{X}$. Thus, for these subjects, the class-consistent performances during the $\mathrm{J}-\mathrm{C}$, $\mathrm{XF}-\mathrm{G}$, and subsequent transfer tests probably were demonstrations of generalized conditional responding (Saunders et al., 1999; Saunders and Spradlin, 1990; Smeets et al., 2001).

\section{General discussion}

The present study demonstrated that transfer of discriminative functions and emergent matching performances based on these functions are sensitive to the order in which prerequisite lower-order and higher-order tasks are trained. In Experiment
1, simple $\mathrm{A}$ and $\mathrm{B}$ discrimination tasks were trained before the A discrimination performances were brought under control of $\mathbf{J}$ stimuli $(\mathbf{J}-\mathbf{A})$. Likewise, conditional $\mathrm{D}-\mathrm{E}$ and $\mathrm{F}-\mathrm{G}$ discrimination tasks were trained before the $\mathrm{D}-\mathrm{E}$ relations were brought under contextual control of $\mathrm{X}$ stimuli (XD-E). All subjects demonstrated transfer of control from A to $\mathbf{J}(\mathrm{J} 1+/ \mathbf{J} 2-)$ and from $\mathrm{D}-\mathrm{E}$ to $\mathrm{X}(\mathrm{X} 1+/ \mathrm{X} 2-)$. Almost all subjects matched the $\mathrm{J}, \mathrm{X}$, and $\mathrm{A}$ stimuli with other experimental stimulus configurations (e.g. J-B, $\mathrm{XD}-\mathrm{E}, \mathrm{J}-\mathrm{DE}, \mathrm{X}-\mathrm{A}$ ) and with newly introduced stimulus configurations of same discriminative properties (e.g. JH-H, J-words). These performances did not occur, at least reliably, when the higher-order tasks were trained before the lowerorder tasks (e.g. training XD-E before D-E and $\mathrm{F}-\mathrm{G})$.

The order effect could be related to the fact that the subjects received transfer training in Experiment 1 but not in Experiment 2. In Experiment 1, the A, B (and C) discriminations were trained first. Thus, $\mathrm{A} 1$ and $\mathrm{B} 1$ acquired an $\mathrm{S}+$ function, and $\mathrm{A} 2$ and $\mathrm{B} 2$ an $\mathrm{S}-$ function. During the subsequent $\mathrm{J}_{-}$ A training, the subjects learned to choose the $\mathrm{S}+$ when given $\mathrm{J} 1$ and to choose the $\mathrm{S}-$ when given J2. Hence, transfer of discriminative functions should be expected (De Rose et al., 1988; Smeets, 1994; Sidman, 1994, 2000). From that point on, the subjects did as before and selected $\mathrm{S}+$ during simple discrimination probes $(\mathrm{J} 1+/ \mathrm{J} 2-)$, and related $\mathrm{J} 1+$ to $\mathrm{S}+$ configurations and $\mathrm{J} 2-$ to $\mathrm{S}$ - configurations during conditional discrimination probes (first $\mathbf{J}-\mathrm{B}$, later also $\mathrm{JD}-\mathrm{E}, \mathrm{JH}-\mathrm{H}$, and J-words). When trained first (Experiment 2), the $\mathrm{J}-\mathrm{A}$ training did not permit the subjects to relate $\mathrm{J} 1$ to an $\mathrm{S}+$ and $\mathrm{J} 2$ to an $\mathrm{S}-$, because the $\mathrm{A}$ stimuli had not acquired these functions yet. Instead, the $\mathbf{J}-\mathrm{A}$ training produced two sets of discriminative JA compounds: $\mathrm{J} 1 \mathrm{~A} 1+, \mathrm{J} 2 \mathrm{~A} 2+$, and $\mathrm{J} 1 \mathrm{~A} 2-, \mathrm{J} 2 \mathrm{~A} 1-$. When at that point the $\mathrm{A}$ discrimination was trained, the subjects had no basis to attach the $\mathrm{S}+$ and $\mathrm{S}-$ functions of these stimuli to the $\mathrm{J}$ elements of the $\mathrm{S}+$ compounds ( $\mathrm{J} 1 \mathrm{~A} 1, \mathrm{~A} 1+$, hence $\mathrm{J} 1+; \mathrm{J} 2 \mathrm{~A} 2$, $\mathrm{A} 2-$, hence $\mathrm{J} 2-)$, of the $\mathrm{S}-$ compounds (J2A1, A1 + , hence $\mathrm{J} 2+$; $\mathrm{J} 1 \mathrm{~A} 2$, A2 - , hence $\mathrm{J} 1-$ ), or of all four compounds (no basis for transfer). Hence, the results of the $J$ 
discrimination probes and of the subsequent matching probes in which the $\mathbf{J}$ stimuli functioned as samples, were unpredictable.

The same analysis can be applied to the D-E, $\mathrm{F}-\mathrm{G}$, and $\mathrm{XD}-\mathrm{E}$ training phases. In Experiment 1 , the $\mathrm{D}-\mathrm{E}$ and $\mathrm{F}-\mathrm{G}$ relations were trained first. This training led to the formation of four compounds with an $\mathrm{S}+$ function (D1E1, D2E2, F1G1, F2G2) and four compounds with a $\mathrm{S}$ - function (D1E2, D2E1, F1G2, F2G1). During the subsequent $\mathrm{XD}-\mathrm{E}$ training, the subjects related $\mathrm{X} 1$ to a subset of $\mathrm{S}+$ stimuli (D1E1, D2E2) and X2 to a subset of $\mathrm{S}-$ stimuli (D1E2, D2E1), so that transfer should be expected $(\mathrm{X} 1+, \mathrm{X} 2-)$. In effect, when given the $\mathrm{X}$ discrimination task, the subjects selected $\mathrm{X} 1+$, and when given the $\mathrm{XF}-\mathrm{G}$, $\mathrm{X}-\mathrm{A}, \mathrm{XH}-\mathrm{H}$, and $\mathrm{X}$-words probes, they did as before and matched the $\mathrm{X}$ stimuli with stimulus configurations of same discriminative functions. When trained first (Experiment 2), the XD-E training did not permit the subjects to relate $\mathrm{X} 1$ to $\mathrm{S}+$ and $\mathrm{X} 2$ to $\mathrm{S}-$ because the DE configurations had not acquired these properties yet. In stead, the XD-E training produced three-element discriminative compounds (X1D1E1+, X1D2E2+. $\mathrm{X} 1 \mathrm{D} 1 \mathrm{E} 2-, \mathrm{X} 1 \mathrm{D} 2 \mathrm{E} 1-, \mathrm{X} 2 \mathrm{D} 1 \mathrm{E} 1-, \mathrm{X} 2 \mathrm{D} 2 \mathrm{E} 2-$, $\mathrm{X} 2 \mathrm{D} 1 \mathrm{E} 2+, \mathrm{X} 2 \mathrm{D} 2 \mathrm{E} 1-$ ). When at that point the $\mathrm{D}-\mathrm{E}$ training was introduced, the discriminative functions of the newly produced DE compounds could be attached to the X elements of the XDE compounds with $\mathrm{S}+$ functions (e.g. X1D1E1, $\mathrm{D} 1 \mathrm{E} 1+$, hence $\mathrm{X} 1+$; X2D1E2, D1E2 - , hence $\mathrm{X} 2-$ ), of the XDE compounds with $\mathrm{S}-$ functions (X2D1E1, D1E1+, hence X2+; X1D1E2, D1E2 -, hence X1-), or of all XDE compounds. Thus the outcome of the $\mathrm{X}$ discrimination test and of the matching probes in which the $\mathrm{X}$ stimuli functioned as samples would be difficult to predict.

The above analysis may also explain why in other studies involving similar four- and five-term contingency tasks, four-term/five-term contingency sequences produced contextual control over transitivity relations (Kennedy and Laitinen, 1988), whereas five-term/four-term contingency sequences did not or only with great difficulty (Kennedy and Laitinen, 1988; Bush et al., 1989).

In the Kennedy and Laitinen (1988) study, subjects receiving the four-term/five-term contin- gency first received training on A-B, A-C, and A$\mathrm{D}$ tasks. Based on our analysis, this training should have produced discriminative $\mathrm{AB}, \mathrm{AC}$, and $\mathrm{AD}$ compounds and, as a result thereof, $\mathrm{BC}$ compounds with corresponding discriminative functions (e.g. $\mathrm{B} 1 \mathrm{C} 1+, \mathrm{B} 1 \mathrm{C} 2-$ ) (Pérez-González, 2001; Smeets et al., 2000). Then the baseline relations were brought under contextual control of novel X stimuli (XA-B, XA-C, XA-D) and the subjects were trained to select $\mathrm{S}+$ configurations (e.g. A1B1) when given $\mathrm{X} 1$, and to select $\mathrm{S}-$ configurations (e.g. A1B2) when given X2. Thus, when given the opportunity to demonstrate contextual control over transitivity relations, the subjects did as before and matched $\mathrm{X} 1$ with $\mathrm{S}+$ (e.g. B1C1) and X2 with $\mathrm{S}-(\mathrm{B} 1 \mathrm{C} 2)$. By contrast, when XA-B, XA-C, and XA-D were trained first, the subjects did not relate the $\mathrm{X}$ stimuli to other stimuli with $\mathrm{S}+$ and $\mathrm{S}-$ functions. Instead, discriminative $\mathrm{XAB}, \mathrm{XAC}$, and XAD compounds were formed. Hence, when the subjects received subsequent A-B, A-C, and A-D training, transfer from $\mathrm{AB}$ and $\mathrm{AC}$ to $\mathrm{BC}$ should be unimpaired (Pérez-González, 2001; Smeets et al., 2000) whereas the XBC performances would be difficult to predict because the subjects had no basis for relating $\mathrm{X} 1$ to stimulus configurations with $\mathrm{S}+$ functions and $\mathrm{X} 2$ to configurations with $\mathrm{S}-$ functions.

\section{References}

Adams, B.J., Fields, L., Verhave, T., 1993. Effects of test order on intersubject variability during equivalence class formation. The Psychological Record 43, 133-152.

Barnes-Holmes, D., Keane, J., Barnes-Holmes, Y., Smeets, P.M., 2000. A derived transfer of emotive functions as a means of establishing differential preferences for soft drinks. The Psychological Record 50, 493-511.

Bush, K.M., Sidman, M., De Rose, T., 1989. Contextual control of emergent equivalence relations. Journal of the Experimental Analysis of Behavior 51, 29-45.

Carpentier, F., Smeets, P.M., Barnes-Holmes, D., 2002a. Establishing transfer of compound control in children: a stimulus control analysis. The Psychological Record 52, $139-158$.

Carpentier, F., Smeets, P.M., Barnes-Holmes, D. 2002b. Class formation of unrelated stimuli with same discriminative functions. European Journal of Behavior Analysis. 3, 7-19. 
Cohen, J.D., MacWhinney, B., Flatt, M., Provost, J., 1993. Psyscope: a new graphic interactive environment for designing psychology experiments. Behavioral Research Methods, Instruments, Computers 25, 257-271.

De Rose, J.C., Mcllvane, W.J., Dube, W.V., Galpin, V.C., Stoddard, L.T., 1988. Emergent simple discrimination established by indirect relation to differential consequences. Journal of the Experimental Analysis of Behavior 50, 1-20.

Dougher, M.J., Markham, M.R., 1994. Stimulus equivalence, functional equivalence, and the transfer of function. In: Hayes, S.C., Hayes, L.J., Sato, M., Ono, K. (Eds.), Behavior Analysis in Language and Cognition. Context Press, Reno, NV, pp. 71-90.

Dube, W.V., Mclvane, W.J., 1995. Stimulus-reinforcer relations and emergent matching to sample. The Psychological Record 45, 591-612.

Dube, W.V., McIlvane, W.J., Maguire, R.W., Mackay, H.A., Stoddard, L.T., 1989. Stimulus class formation and stimulus-reinforcer relations. Journal of the Experimental Analysis of Behavior 51, 65-76.

Fields, L., Varelas, A., Reeve, K.F., Belanich, J., Wadhwa, P., DeRosse, P., Rosen, D., 2000. Effects of prior conditional discrimination training, symmetry, transitivity, and equivalence testing on the emergence of new equivalence classes. The Psychological Record 50, 443-466.

Kennedy, C.H., Laitinen, R., 1988. Second-order conditional control of symmetric and transitive stimulus relations: the influence of order effects. The Psychological Record 38, 437-446.

Pérez-González, L.A., 1994. Transfer of relational stimulus control in conditional discriminations. Journal of the Experimental Analysis of Behavior 61, 487-503.

Pérez-González, L.A., 2001. Concept formation based on the relations among values of multi-component figures. Behavioural Processes 56, 1-14.
Pérez-González, L.A., Serna, R.W. (in press). Transfer of specific contextual functions to novel conditional discriminations, Journal of the Experimental Analysis of Behavior.

Saunders, K.J., Spradlin, J.E., 1990. Conditional discrimination in mentally retarded adults: the development of generalized skills. Journal of the Experimental Analysis of Behavior 54, 239-250.

Saunders, R.R., Drake, K., Spradlin, J.E., 1999. Equivalence class establishment, expansion, and modification in preschool children. Journal of the Experimental Analysis of Behavior 71, 195-214.

Schenk, J.J., 1994. Emergent relations of equivalence generated by outcome-specific consequences in conditional discrimination. The Psychological Record 44, 537-558.

Sidman, M., 1994. Equivalence Relations and Behavior: a Research Story. Authors Cooperative, Boston, MA.

Sidman, M., 2000. Equivalence relations and the reinforcement contingency. Journal of the Experimental Analysis of Behavior 74, 127-146.

Sidman, M., Kirk, B., Willson-Morris, M., 1985. Six-member stimulus classes generated by conditional-discrimination procedures. Journal of the Experimental Analysis of Behavior 43, 21-42.

Smeets, P.M., 1994. Stability of emergent simple discriminations in young children. Journal of Experimental Child Psychology 57, 397-417.

Smeets, P.M., Barnes-Holmes, D., Cullinan, V., 2000. Establishing equivalence classes with match-to-sample format and simultaneous-discrimination format conditional discrimination tasks. The Psychological Record 50, 721-744.

Smeets, P.M., Barnes-Holmes, D., Roche, B., 2001. Derived stimulus-response and stimulus-stimulus relations in children and adults: assessing training order effects. Journal of Experimental Child Psychology 78, 130-154.

Stromer, R., McIlvane, W.J., Serna, R.W., 1993. Complex stimulus control and equivalence. The Psychological Record 43, 585-598. 